\title{
Development of a Real-Time Cell Analysing (RTCA) method as a fast and accurate screen for the selection of chikungunya virus replication inhibitors
}

\author{
Suria Marlina, Meng-Hooi Shu, Sazaly AbuBakar and Keivan Zandi
}

\begin{abstract}
Background: The xCELLigence real-time cell analysis (RTCA) system is an established electronic cell sensor array. This system uses microelectronic biosensor technology that is verified for real-time, label-free, dynamic and non-offensive monitoring of cellular features, including detection of viral cytopathic effect (CPE). Screening viral replication inhibitors based on presence of CPE has been applied for different viruses, including chikungunya virus (CHIKV). However, most CPE-based methods, including MTT and MTS assays, do not provide information on the initiation of CPE nor the changes in reaction rate of the virus propagation over time. Therefore, in this study we developed an RTCA method as an accurate and time-based screen for antiviral compounds against CHIKV.
\end{abstract}

Methods: CHIKV-infected Vero cells were used as an in vitro model to establish the suitability of the RTCA system as a quantitative analysis method based on the induction of CPE. We also performed an MTS assay as a CPE-based conventional method. Experimental assays were carried out to evaluate the optimal seeding density of the Vero cells, cytotoxicity of the tested compounds, titration of CHIKV and the antiviral activity of ribavirin, which has been reported as an effective compound against CHIKV in vitro replication.

Results: The optimal time point for viral inoculation was $18 \mathrm{~h}$ after seeding the cells. We determined that the maximum non-toxic dose (MNTD) of ribavirin was $200 \mu \mathrm{g} / \mathrm{ml}$ for Vero cells. Regarding the dynamic monitoring of Vero cell properties during antiviral assay, approximately $34 \mathrm{~h}$ post-infection, the normalised Cell Index (Cl) values of CHIKV-infected Vero cells started to decrease, while the vehicle controls did not show any significant changes. We also successfully showed the dose dependent manner of ribavirin as an approved in vitro inhibitor for CHIKV through our RTCA experiment.

Conclusion: RTCA technology could become the prevailing tool in antiviral research due to its accurate output and the opportunity to carry out quality control and technical optimisation.

Keywords: Real-time cell analysis, Cytopathogenicity, Antiviral screening, Chikungunya, Ribavirin

\footnotetext{
*Correspondence: keivan@um.edu.my

Tropical Infectious Diseases Research and Education Centre (TIDREC),

Department of Medical Microbiology, Faculty of Medicine, University of

Malaya, Kuala Lumpur, Malaysia
}

(c) 2015 Marlina et al. Open Access This article is distributed under the terms of the Creative Commons Attribution 4.0 International License (http://creativecommons.org/licenses/by/4.0/), which permits unrestricted use, distribution, and reproduction in any medium, provided you give appropriate credit to the original author(s) and the source, provide a link to the Creative Commons license, and indicate if changes were made. The Creative Commons Public Domain Dedication waiver (http://creativecommons.org/publicdomain/zero/1.0/) applies to the data made available in this article, unless otherwise stated. 


\section{Background}

Chikungunya virus (CHIKV) is an enveloped arbovirus with a positive-sense single-stranded RNA genome and belongs to the Togaviridae family [1]. CHIKV is transmitted to humans via bites from infected Aedes mosquitoes. CHIKV can be detected as early as 4 days post-infection in the saliva of the mosquitoes, which indicates a short period of extrinsic incubation [2]. Chikungunya is a Makonde word for "that which bends up" describing the contorted posture and unbearably painful rheumatic manifestations experienced by infected patients [3]. Since 2004, millions of cases of CHIKV infection have been reported in the Americas, Africa, Asia, Europe and Indian Ocean islands [4]. CHIKV outbreaks give rise to a grim economic burden on the affected regions, especially in the tropical and sub-tropical parts of the world, as the available treatment approaches, including fluid transfusion, bed rest and the use of antipyretics and analgesics can only alleviate the disease manifestation. In addition, vaccines against CHIKV have so far shown to be an intractable approach and there are no definite treatments against CHIKV infections [5]. Therefore, finding effective antiviral compounds against $\mathrm{CHIKV}$ is crucial.

In early studies, the methods and techniques used to examine antiviral agents included plaque reduction assay and MTT [3-(4, 5-dimethylthiazol-2-yl)-2, 5diphenyltetrazoliumbromide] cell proliferation assay. Plaque reduction assay is still extensively practised as the gold standard for quantifying the lytic activity of viruses, which is observed in an infected confluent cell through macroscopic analysis of viral plaques prior to dye staining, with crystal violet, for example. The viral titres can be efficiently determined using this technique, as an end-point assay, although the method's inadequacy regarding CPE onset and the kinetics of viral replication is markedly noted. Furthermore, infections with a diminished number of viruses and $\mathrm{pH}$ of the medium generate minute unclear plaques that are difficult to detect, or create no plaque in spite of virus replication [6].

MTT and MTS cell proliferation assays are enzymebased assays that evaluate the activity of mitochondrial dehydrogenase in cells whereby mitochondrial NADH condenses MTT and also MTS to purple formazan. Basically, the colour concentration of formazan dye is associated with the number of vital cells [7]. However, these assays are time consuming in that they are labour intensive, requiring assessment by microscopic observation for quality control. Hence, an automated assay that monitors the biology of a cell in real-time is sought-after.

The xCELLigence real-time cell analysis (RTCA) system is an advanced technology, which allows real-time cell growth monitoring using a label-free cell-based assay that measures impedance variations in the culture media. This system has been applied in microbiological research [8], environmental toxicity [9] and cellular function [10]. Detailed and assorted aspects of cellular processes related to adhesion and morphology of cells, including cytotoxicity, cell proliferation, receptor-mediated signalling and migration can be analysed with RTCA [11]. In this system, to determine electronic impedance, cell culture wells are equipped with microelectrodes in the base, which attach to cultured cells through their sensors and record any changes. The microelectrodes are incorporated in special cell culture plates, E-Plates. In addition, the electrical impedance measured is based on cell status, termed CI [12]. The electrode impedance is exhibited and set down as the $\mathrm{CI}$ value to exemplify the differences in cell number, adhesion degree, cellular morphology and viability.

In our present study, we aim to investigate the efficacy of RTCA in the screening of antiviral drugs for CHIKV. Ribavirin, an approved in vitro inhibitor agent against CHIKV, was used in our investigation. Ribavirin has been shown to decrease CHIKV-induced arthritis and was found to be beneficial in resolving joint and soft tissue swelling $[13,14]$.

\section{Method \\ Cell and virus}

Vero cells, which are extracted from an African green monkey kidney-derived cell line CCL81, were obtained from the ATCC (Manassas, VA, USA). The adherent cell line was maintained in Eagle's Minimum Essential Medium (EMEM; Gibco, Carlsbad, CA, USA) supplemented with $10 \%$ foetal bovine serum (FBS; Gibco, Carlsbad, CA, USA). Cells were cultured in a humidified atmosphere with $5 \% \mathrm{CO}_{2}$ at $37{ }^{\circ} \mathrm{C}$. The CHIKV strain used in this experiment was a clinical isolate from an outbreak in Johor in 2008, coded as MY/065/08/ FN295485. It belongs to the ECSA genotype and has the A226V mutation in the E1 protein [15]. The CHIKV was then propagated on Vero cells, followed by the virus, using tissue culture infectious dose $50\left(\mathrm{TCID}_{50}\right)$ methods [16]. Then, the virus stock was aliquoted and stored at $-80{ }^{\circ} \mathrm{C}$ until needed. At the time of virus propagation and antiviral assays, the percentage of FBS in the cell culture media decreased to $2 \%$.

\section{Chemicals}

Ribavirin (Sigma-Aldrich, St. Louis, MO, USA) and cisplatin (Sigma-Aldrich, St. Louis, MO, USA) were dissolved in dimethyl sulfoxide (DMSO, Sigma-Aldrich) to prepare 50 and $1 \mathrm{mg} / \mathrm{ml}$ stock solutions, respectively. The stock solutions were aliquoted and stored at $-20{ }^{\circ} \mathrm{C}$ for future experiments.

\section{Real-time cell analysis system}

The RTCA system comprises four main components: an electronic sensor analyser, a device station, a control unit 
and E-Plate 96. The software used in the study was RTCA Software 2.0 (Roche), which has the advantages of a user-friendly interface and electronic recording of the experimental details. The voltage for the RTCA analyser was between 100 and $240 \mathrm{~V}$ and the frequency was 50 to $60 \mathrm{~Hz}$. The device station, which was placed inside the incubator, was able to switch any wells from E-plate 96 to the RTCA analyser for the impedance measurement. The CI value was a parameter that reflected the cell profile based on the impedance measurement. The $\mathrm{CI}$ value was zero in the absence or non-adherence of cells to the electrodes. In contrast, CI values increased gradually and consistently as cells attached to the electrodes. Additionally, the CI value measured the adherent degree of the cells. The degree of cell adhesion can be categorised into three degrees where a CI value of 1 to 4 is weak, 5 to 10 is considered moderate to strong and 10 to 15 denotes strongly adhered cells [17].

\section{Cell growth and proliferation assay using RTCA}

The growth, proliferation and adhesion kinetics of Vero cells were determined using RTCA technology (ACEA Biosciences, San Diego, CA USA) as previously described with some minor modifications [18]. Briefly, $50 \mu \mathrm{l}$ of EMEM supplemented with $10 \%$ FBS (cell culture medium) was placed in each well of the E-plate 96 (gold-microelectrode array integrated E-plate; ACEA Biosciences, San Diego, CA USA). E-plate 96 was then connected to the system to obtain background impedance readings. This was to ensure that all wells of E-plate 96 and the connections were in good condition so as to avoid compromising the interpretation of the results. Serial dilutions of $2.0 \times 10^{4}, 1.8 \times 10^{4}$ and $1.5 \times 10^{4}$ cells in $50 \mu \mathrm{l}$ were prepared, four replicates in each of the concentrations. These serial dilutions of cell suspensions were added to the wells containing $50 \mu \mathrm{l}$ of culture medium. The E-plates were incubated at room temperature for $30 \mathrm{~min}$ in a laminar flow cabinet and then placed on the RTCA SP Station located in an incubator at $37^{\circ} \mathrm{C}$ for continuous impedance recording. $\mathrm{CI}$ values measured by continuous impedance recordings every $2 \mathrm{mi}-$ nutes reflected the cell activities.

\section{Real-time monitoring of cytotoxicity assay of ribavirin and virus-induced cytopathogenicity using RTCA}

RTCA was used to evaluate the in vitro cytotoxicity of ribavirin and also CHIKV-induced cytopathogenicity by profiling the adhesion, growth and proliferation kinetics of Vero cells in response to treatment. In brief, based on data from the cell growth and proliferation assay, $1.8 \times$ $10^{4}$ cells were seeded in E-plate 96 followed by incubation at $37{ }^{\circ} \mathrm{C}$ with $5 \% \mathrm{CO}_{2}$. Proliferation, spreading and cell attachment kinetics were monitored every $2 \mathrm{mi}$ nutes. When the cells reached the logarithmic growth phase, two-fold serial dilutions of ribavirin ranging from
200, 100, 50, 25 and $12.5 \mu \mathrm{g} / \mathrm{ml}$ were added to the wells of E-plate 96 in triplicate. The plate was then incubated at room temperature for $30 \mathrm{~min}$ and then placed on the RTCA SP Station for continuous impedance recording every 2 minutes.

As for virus titration assay, CHIKV stock was prepared in 10-fold dilutions at concentrations of $1 \times 10^{-1}, 1 \times 10^{-2}$, $1 \times 10^{-3}, 1 \times 10^{-4}, 1 \times 10^{-5}$ and $1 \times 10^{-6}$ in EMEM supplemented with $2 \%$ FBS. The plate was then incubated at $37{ }^{\circ} \mathrm{C}$ for 1 hour followed by washing with sterile PBS three times to remove the unabsorbed viruses. When the cells reached the logarithmic growth phase, the cell culture media in the wells were replaced by $100 \mu \mathrm{l}$ of viral suspensions in triplicate. Then, $100 \mu \mathrm{l}$ of EMEM supplemented with $2 \%$ FBS was added to each well and the plate was placed on the RTCA SP Station at $37{ }^{\circ} \mathrm{C}$ with $5 \% \mathrm{CO}_{2}$ for continuous impedance recording every two minutes.

\section{Real-time cell growth profiling for antiviral assay using RTCA}

RTCA was used to profile the adhesion, growth and proliferation kinetics for antiviral assay. Vero cells were seeded in E-plate 96 at a concentration determined from the cell growth and proliferation assay, and incubated at $37{ }^{\circ} \mathrm{C}$. When the cells reached the logarithmic growth phase, the plate was detached from the RTCA SP Station. The remaining media were taken out from E-plate 96 and $100 \mu \mathrm{l}$ virus suspension $(\mathrm{MOI}=1)$ was added to each well. After 1 hour incubation at $37{ }^{\circ} \mathrm{C}$ viral inocula were replaced by $200 \mu \mathrm{l}$ of increasing concentrations of the tested compounds, accordingly. Depending on the preliminary cytotoxicity data, ribavirin was prepared in serial dilutions of $50,25,12.5$ and $6.25 \mu \mathrm{g} / \mathrm{ml}$. For vehicle cell control, all the wells were replaced by adding the $200 \mu \mathrm{l}$ of cell culture medium with $2 \%$ FBS. E-Plate 96 was then incubated in the RTCA SP Station inside the incubator and the CI values were recorded every 2 minutes.

\section{Investigating acute drug responsiveness by RTCA}

As a further study on the rapid detection of cytotoxicity by RTCA, Vero cells were treated with cisplatin as a compound with known potent cytotoxicity. The cells were prepared in EMEM supplemented with $10 \%$ FBS and seeded in an E-Plate at a density of $1.8 \times 10^{4}$ cells per well. The cisplatin was prepared in concentrations of 8, 6, 4, 2 and $0.5 \mu \mathrm{g} / \mathrm{ml}$ in EMEM supplemented with $2 \%$ FBS. The plate was then incubated at room temperature for $30 \mathrm{~min}$ after adding the different concentrations of cisplatin in triplicate. Then, the plate was placed on the RTCA SP Station at $37{ }^{\circ} \mathrm{C}$ with $5 \% \mathrm{CO}_{2}$ for continuous impedance recording every 2 minutes. 


\section{Cell morphology analysis}

As a parallel comparison to both cytotoxicity and antiviral assay conducted by RTCA and MTS assay, the Vero cells were seeded in two different 96-well plates (Nunclon). The cell morphology was observed through inverted microscopy prior to MTS assay. The cells were visualised and their images were captured with a Zeiss Telaval 31 microscope after $72 \mathrm{~h}$ of incubation for both cytotoxicity and antiviral assays.

\section{Cytotoxicity assay of ribavirin and cisplatin using MTS}

MTS assay as an approved cytotoxicity test was performed to determine the non-toxic concentrations of both ribavirin and cisplatin on Vero cells using an MTS (3-(4, 5-dimethylthiazol-2-yl)-5-(3-carboxymethoxyphenyl)-2-(4-sulfophenyl)-2H-tetrazolium) kit (Promega, USA) according to the manufacturer's protocol. In short, the Vero cells were grown in 96-well plates and were treated with increasing concentrations of ribavirin and cisplatin in triplicate. The cytotoxicity assay was conducted for 48 and $72 \mathrm{~h}$ post-treatment, respectively. Subsequently, MTS solution was added to each well and incubated for 4 hours at $37{ }^{\circ} \mathrm{C}$ with $5 \% \mathrm{CO}_{2}$ followed by an absorbance reading at the $490 \mathrm{~nm}$ wavelength using Infinite 200 Pro-multiplate reader (Tecan, Männedorf, Switzerland).

\section{Antiviral assay using MTS}

To identify the half maximal inhibitory concentration $\left(\mathrm{IC}_{50}\right)$ of ribavirin against CHIKV-infected Vero cells, antiviral assay was conducted by MTS assay (Promega, USA) according to the manufacturer's protocol. The Vero cells were grown in two different 96-well plates and were treated with different concentrations of ribavirin in triplicate after CHIKV inoculation of the cells. The plates were then incubated for 48 and $72 \mathrm{~h}$ at $37{ }^{\circ} \mathrm{C}$ with $5 \% \mathrm{CO}_{2}$ prior to MTS assay. Subsequently, MTS solution was added to the cells and incubated for 4 hours at $37{ }^{\circ} \mathrm{C}$ with $5 \% \mathrm{CO}_{2}$ followed by an absorbance reading at the $490 \mathrm{~nm}$ wavelength using the Infinite 200 Pro-multiplate reader (Tecan, Männedorf, Switzerland).

\section{Data analysis}

The half maximal cytotoxic concentration $\left(\mathrm{CC}_{50}\right)$ and inhibitory concentration $\left(\mathrm{IC}_{50}\right)$ for the MTS assay was determined by Graph Pad Prism 5 (Graph Pad Software Inc., San Diego, CA, USA, 2005). A nonlinear regression was run to evaluate the association between the dosedependent manner of the compound and antiviral activities of Vero cells. For RTCA data analysis, the normalised $\mathrm{CI}$ value was calculated for each sample well by normalising the $\mathrm{CI}$ value to a suitable time point prior to the treatment or infection. Fundamentally, the normalised CI value, $\mathrm{CC}_{50}$ and $\mathrm{IC}_{50}$ were automatically calculated by RTCA Software 2.0 (Roche). CI normalisation is essential to provide an accurate estimation of the percentage of cell adhesion, as it eliminates redundant data and secures the loading of the associated data.

\section{Results}

\section{Monitoring of cell growth and proliferation}

In this study, a cell proliferation analysis was performed using Vero cells to get the optimum cell number seeded in E-Plate 96 and to distinguish the optimal time point for viral infection prior to the antiviral assay. RTCA software was used to determine $\mathrm{CI}$ values through the measured impedance recordings.

Three different cell densities of $2.0 \times 10^{4}, 1.8 \times 10^{4}$ and $1.5 \times 10^{4}$ cells were used in the experiment. As shown in Fig. 1, the preliminary phase of cell adhesion and proliferation was from 0 to $18 \mathrm{~h}$ after cell seeding, indicating the potential time point for the infection and treatment. The maximum CI value of 6.56 can be classified as a moderate to strong degree of cell adhesion (Fig. 1). The curves for all different densities of seeded Vero cells did not exhibit significant differences, therefore, as the median value of three different cell densities, $1.8 \times 10^{4}$ was selected as the optimum number for cell seeding. The optimal time point for viral infection of $1.8 \times 10^{4}$ cells was defined at $18 \mathrm{~h}$ after cell seeding.

\section{Cytotoxicity assay of ribavirin and cisplatin}

Cytotoxicity assay was performed to identify the $\mathrm{CC}_{50}$ of the compounds. The cytotoxicity of ribavirin and cisplatin was analysed by both RTCA and MTS methods. It was found that there was no significant cytotoxicity for all tested concentrations of ribavirin in Vero cells. The optimal treatment time point for both compounds was at approximately $19 \mathrm{~h}$. The CI value was normalised to the suitable time point after treatment, which was $26 \mathrm{~h}$, so as to eliminate the redundant data. The results showed that more than $90 \%$ of the cells treated with $200 \mu \mathrm{g} / \mathrm{ml}$ of ribavirin were viable (Fig. 2). The curves in Fig. 2a illustrated by RTCA show that the ribavirin does not restrict the impedance measurement even at the highest concentration, which indicates that $200 \mu \mathrm{g} / \mathrm{ml}$ of ribavirin does not show toxicity in Vero cells. We have also shown that ribavirin treated-Vero cells do not display significant changes in cellular morphology (Fig. 3).

The results for cytotoxicity of cisplatin in Vero cells are illustrated in Fig. 4. It has been shown that approximately $15 \mathrm{~h}$ post-treatment, the $\mathrm{CI}$ value of Vero cells treated with $8 \mu \mathrm{g} / \mathrm{ml}$ of cisplatin start to decline, followed by cells treated with $6 \mu \mathrm{g} / \mathrm{ml}$ of cisplatin at $21 \mathrm{~h}$ posttreatment (Fig. 4a). The $\mathrm{CC}_{50}$ obtained from RTCA was $5.620 \mu \mathrm{g} / \mathrm{ml}$ for both days two and three post-treatment, respectively. Nevertheless, the $\mathrm{CC}_{50}$ values resulting from MTS assay were 3.409 and $0.033 \mu \mathrm{g} / \mathrm{ml}$ for days two and three post-treatment, respectively (Fig. 4b). 


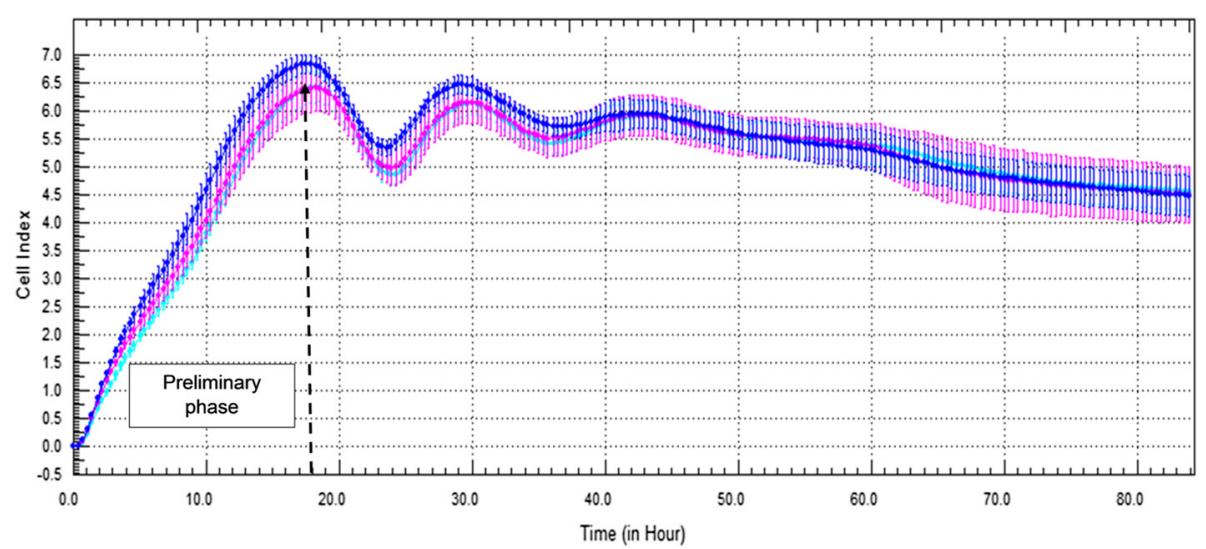

Fig. 1 Proliferation Curve of Vero Cells. The cells that were seeded in E-Plate 96 and were constantly observed by measuring Cl values to obtain the ideal cell number and to distinguish the suitable time point for virus infection prior to the antiviral assay are indicated. Cell features such as adhesion, spreading and proliferation were observed in intervals of 2 minutes. The dash line marks the initial phase of cell adhesion and spreading determined by the $\mathrm{Cl}$ curve of $1.8 \times 10^{4}$ cells at $18 \mathrm{~h}$. Coloured curves represent the various numbers of cells seeded per well in E-Plate 96: Blue line: $2.0 \times 10^{4}$ cells/well; Pink line: $1.8 \times 10^{4}$ cells/well; Turquoise line: $1.5 \times 10^{4}$ cells/well. Each data point signifies the average \pm standard deviation and was analysed in triplicate

\section{Antiviral assay of ribavirin against CHIKV}

Eighteen hours after cell seeding, Vero cells were infected with CHIKV followed by treatment with ribavirin. The results from RTCA showed that the CI values of CHIKVinfected Vero cells started to decrease $34 \mathrm{~h}$ post-infection, while vehicle controls and treated infected-Vero cells did not show any significant changes (Fig. 5a). The results also indicated compliance with the dose-dependent manner for ribavirin treatment, which was verified by the $\mathrm{CI}$ values of Vero cells-infected with CHIKV. The data from MTS assay demonstrated that there was no significant change that could be observed in all concentrations of ribavirintreated cells except for in the lowest concentration of ribavirin (Fig. 5b). This result can also be verified by the cell morphology profiles in Fig. 6. The MTS result exemplified that the $\mathrm{IC}_{50}$ for ribavirin at 48 and $72 \mathrm{~h}$ were 6.12 and $20.34 \mu \mathrm{g} / \mathrm{ml}$, respectively. Meanwhile, the $\mathrm{IC}_{50}$ interpreted by RTCA was $14.78 \mu \mathrm{g} / \mathrm{ml}$ at both 48 and $72 \mathrm{~h}$. a

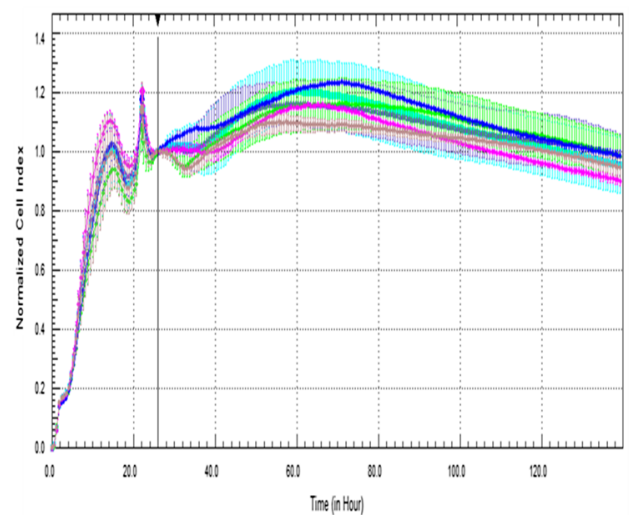

b

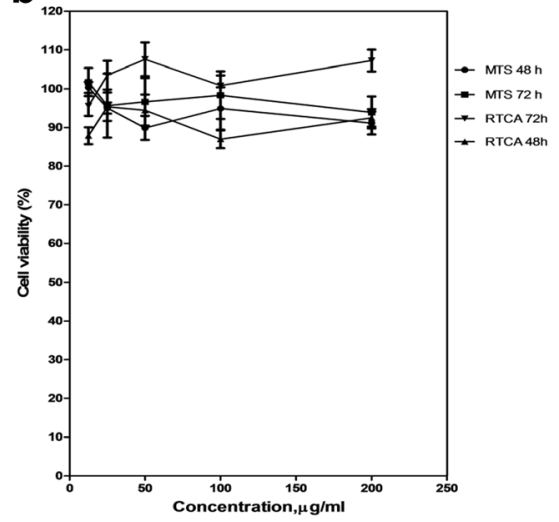

Fig. 2 The Effect of the Intensified Concentrations of Ribavirin on Vero Cells Evaluated by both RTCA and MTS Assays. a The cell proliferation after $138 \mathrm{~h}$ of incubation with increasing concentrations of ribavirin. The black vertical line indicates the normalisation of the $\mathrm{Cl}$ time point at $26 \mathrm{~h}$ subsequent to Vero cells being treated with ribavirin. Coloured curves represent the various serial dilutions of ribavirin. Each data point signifies the average \pm standard deviation and was analysed in triplicate. Blue line: $200 \mu \mathrm{g} / \mathrm{ml}$ ribavirin; Pink line: $100 \mu \mathrm{g} / \mathrm{ml}$ ribavirin; Turquoise line: $50 \mu \mathrm{g} / \mathrm{ml}$ ribavirin; Purple line: $25 \mu \mathrm{g} / \mathrm{ml}$ ribavirin; Grey line: $12.5 \mu \mathrm{g} / \mathrm{ml}$ ribavirin; Green line: negative control (without ribavirin). Each data point signifies the average \pm standard deviation and was analysed in triplicate. $\mathbf{b}$ In comparison to the RTCA assay, this figure indicates that the Vero cells were viable even when treated at the highest concentration of ribavirin on both days two and three, showing minimal cytotoxic effects of the compound on the cells via MTS assay 

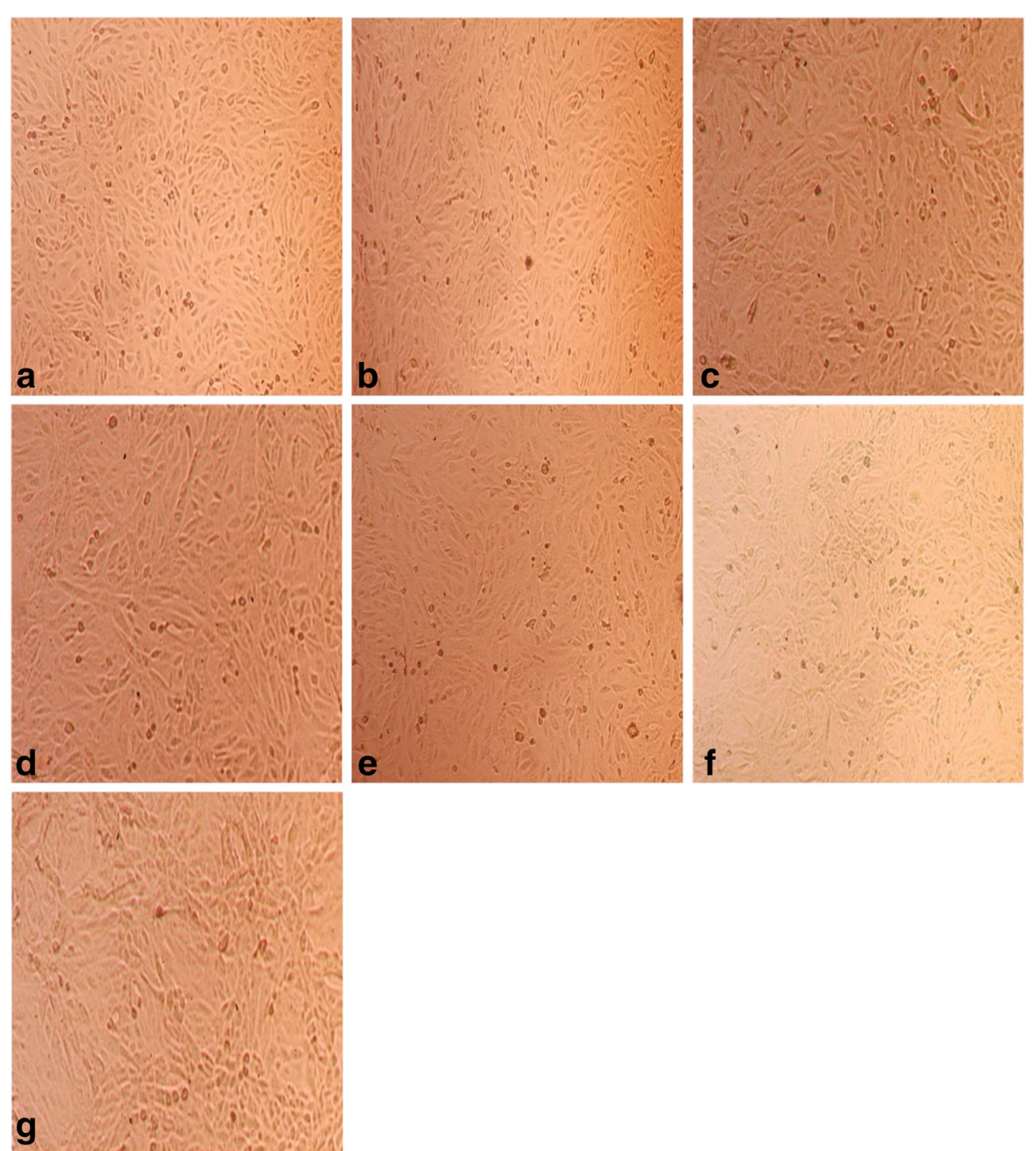

Fig. 3 The Effect of the Intensified Concentrations of Ribavirin on Vero Cell Morphology. The cell morphology profile after $72 \mathrm{~h}$ of incubation after treatment with ribavirin. In parallel comparison to the cytotoxic effect on Vero cells, which was illustrated by RTCA, the cells seeded in a 96-well plate were observed via microscopy. Two-fold serially diluted ribavirin at concentrations of a $200 \mu \mathrm{g} / \mathrm{ml}$, b $100 \mu \mathrm{g} / \mathrm{ml}$, c $50 \mu \mathrm{mg} / \mathrm{ml}$, d $25 \mu \mathrm{gg} / \mathrm{ml}$, e $12.5 \mu \mathrm{gg} / \mathrm{ml}$ and $\mathbf{f} 6.25 \mathrm{\mu g} / \mathrm{ml}$ were used to treat the Vero cells. As a control, $\mathbf{g}$, three wells of non-treated cells were monitored

\section{Viral titration assay}

Viral titration assay was conducted to verify and optimise the viral dose-dependency of CHIKV on RTCA technology. As shown in Fig. 7, the graph curves started to decrease at $18 \mathrm{~h}$ after infection for the highest virus dilution, which was $1 \times 10^{-1}$, and decreased gradually as the dilutions increased, exhibiting a dose-dependent manner for CHIKV infection in Vero cells. The decrease in $\mathrm{CI}$ value indicated cell death as a consequence of CHIKV replication, while in contrast, vehicle control and Vero cells infected with $1 \times 10^{-6}$ dilution of CHIKV did not show any significant change in CI value (Fig. 7). In parallel to this experiment, TCID $_{50}$ of CHIKV was performed in a 96-well plate for the same series of virus concentrations. The $\operatorname{TCID}_{50}$ obtained was $10^{3.5} \mathrm{EID}_{50} / \mathrm{ml}$ for both RTCA and conventional end-point assay.

\section{Discussion}

Nowadays, researchers are adopting advanced technology, such as label-free detection methodologies for cell-based experiments [19]. Cellular activities, including growth inhibition, shape change, spreading, migration and adhered cell degree, can be effectively determined by RTCA technology. Moreover, RTCA is favoured for the efficacy and safety of the experiments [10]. This technology is reasonably consistent and sufficiently dynamic for wide use in medium-throughput screening.

Therefore, in the present study, we aimed to prove the ability of RTCA to detect optimal culture conditions and to examine the reproducibility of cytotoxicity and antiviral assays. Based on the cell growth and proliferation profile measured by RTCA, the curves of initial adhesion of Vero cells were characterised by the sharp rise in CI 

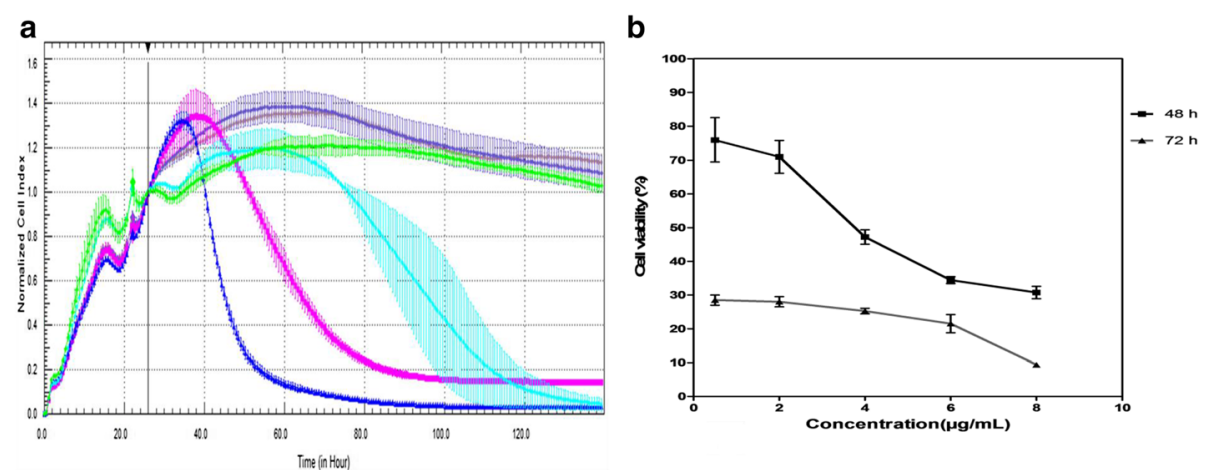

Fig. 4 The Effect of the Intensified Concentrations of Drug-Induced Cytotoxicity on Vero Cells Evaluated by both RTCA and MTS Assays. a Vero cell profile after $138 \mathrm{~h}$ of incubation with increasing concentrations of cisplatin. The black vertical line indicates the normalisation of the $\mathrm{Cl}$ time point at $26 \mathrm{~h}$ subsequent to Vero cells being treated with cisplatin. Coloured curves represent the various concentrations of cisplatin. Each data point signifies the average \pm standard deviation and was analysed in triplicate. Blue line: $8 \mu \mathrm{g} / \mathrm{ml}$ cisplatin; Pink line: $6 \mu \mathrm{g} / \mathrm{ml}$ cisplatin; Turquoise line: $4 \mathrm{\mu g} / \mathrm{ml}$ cisplatin; Purple line: $2 \mathrm{\mu g} / \mathrm{ml}$ cisplatin; Grey line: $0.5 \mu \mathrm{g} / \mathrm{ml}$ cisplatin; Green line: negative control (without cisplatin). Each data point signifies the average \pm standard deviation and was analysed in triplicate. $\mathbf{b}$ Illustration of the curve of cisplatin effects on Vero cells at 48 and $72 \mathrm{~h}$ via MTS assay

value over the $18 \mathrm{~h}$ post-cell seeding and followed by a proliferation period that started to decrease at approximately $48 \mathrm{~h}$ post-cell seeding. The decrease in CI value indicated that the cells were not healthy and cell death was possible. Based on our findings through classic endpoint methods, such as MTT and MTS assays for the CHIKV antiviral assay, which was $72 \mathrm{~h}$ post-infection, we set up the same end point for the reading of our developed RTCA method. Information on behaviour, propagation and fitness of cells through CI value curves was beneficial and enhanced the experimental design compared to conventional in vitro methods, such as MTT and MTS assays whereby the treatments were commonly introduced at a certain time point, technically $24 \mathrm{~h}$ after cell seeding in the plates [13].

As reported by Briolant et al. ribavirin is known as an effective antiviral agent against CHIKV in vitro replication with minimal cytotoxic effects on Vero cells. The results obtained from both methods used in this study showed no cytotoxicity for ribavirin on Vero cells up to $200 \mu \mathrm{g} / \mathrm{ml}$ of the compound. Cisplatin is a chemotherapy drug widely used to treat different types of cancers
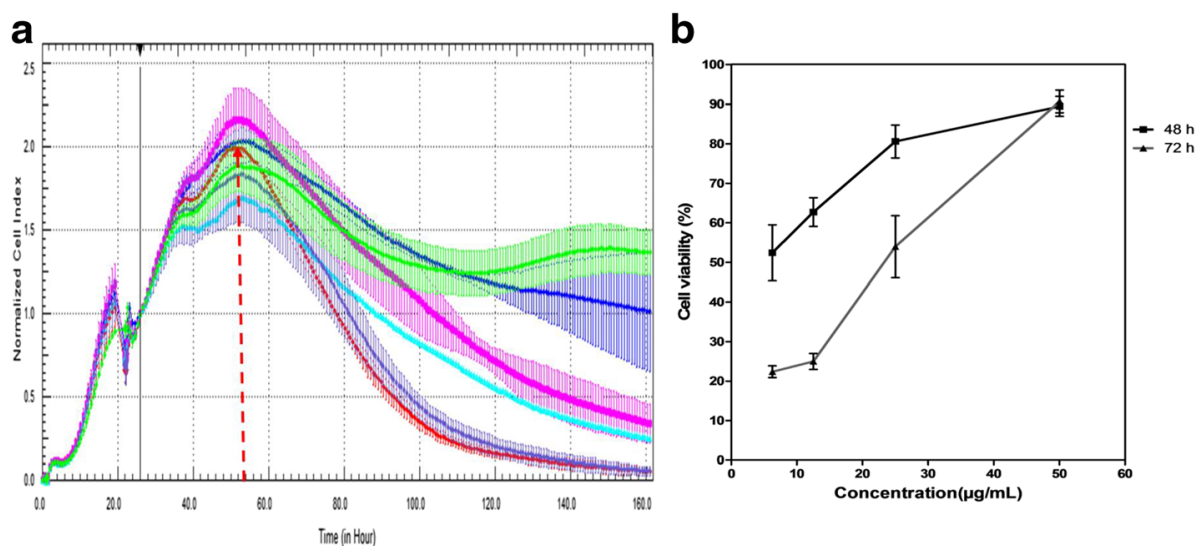

Fig. 5 The Antiviral Effect on Vero Cells Infected with CHIKV Evaluated by both RTCA and MTS Assays. a Measurement of cell impedance every 2 minutes by RTCA monitored the antiviral effect of the various concentrations of ribavirin on the proliferation, spreading and adhesion of cells. The black vertical line indicates the normalisation of the $\mathrm{Cl}$ time point at $26 \mathrm{~h}$ subsequent to treatment of infected Vero cells with ribavirin. The red dash line indicates the onset of declined curved due to infectivity of CHIKV and antiviral activity on Vero cells. Coloured curves represent the Vero cells, viral infected Vero cells and treated viral infected Vero cells with different concentrations of ribavirin. Blue line: $50 \mathrm{\mu g} / \mathrm{ml}$ ribavirin; Pink line: $25 \mathrm{\mu g} / \mathrm{ml}$ ribavirin; Turquoise line: $12.5 \mu \mathrm{g} / \mathrm{ml}$ ribavirin; Purple line: $6.25 \mu \mathrm{g} / \mathrm{ml}$ ribavirin; Red line: positive control (CHIKV infection); Green line: negative control (without CHIKV infection). Each data point signifies the average \pm standard deviation and was analysed in triplicate. $\mathbf{b}$ The curve shows the antiviral activity effects via MTS assays, which can only be obtained at 48 and $72 \mathrm{~h}$ prior to ribavirin treatment of CHIKV-infected Vero cells 

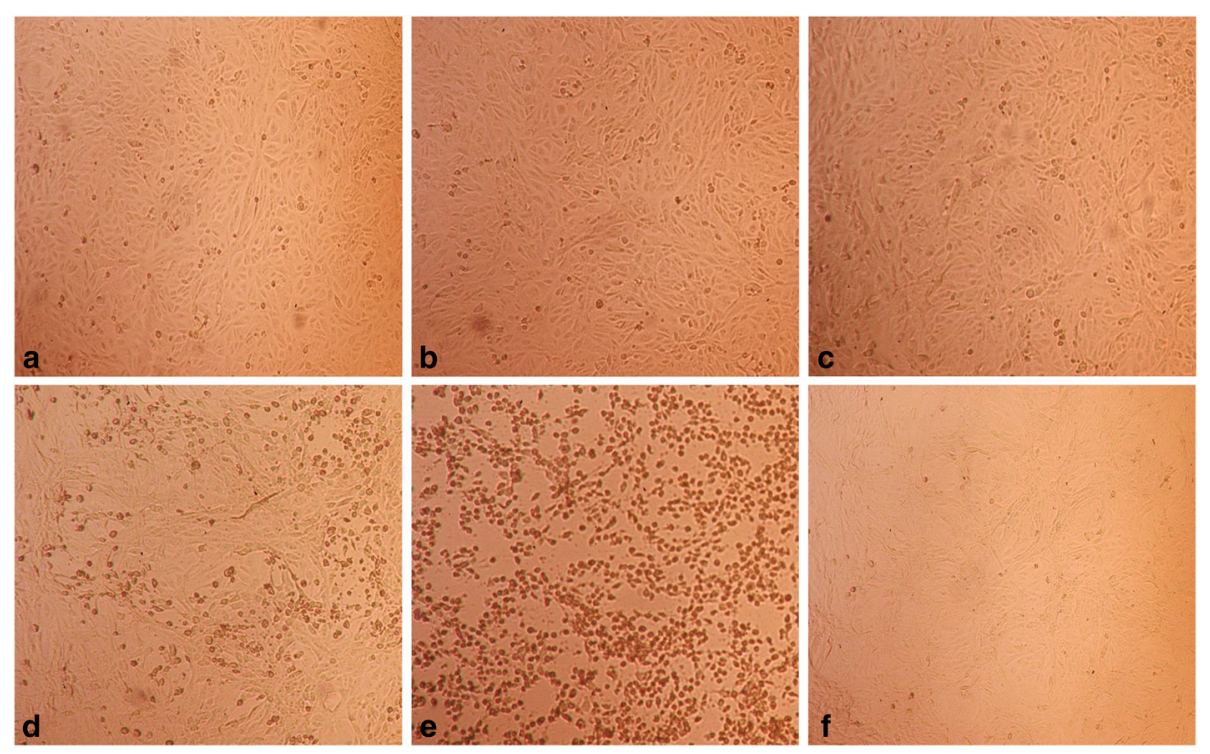

Fig. 6 The Antiviral Effect on Vero Cell Morphology. Cell morphology profile after $72 \mathrm{~h}$ post infection and treatment. In parallel comparison to the antiviral effect on Vero cells, which was indicated by RTCA, the cells were seeded in a 96-well plate and observed via microscopy. CHIKV-infected cells were treated with ribavirin at concentrations of a $50 \mu \mathrm{g} / \mathrm{ml}$, b $25 \mu \mathrm{g} / \mathrm{ml}, \mathbf{c} 12.5 \mu \mathrm{g} / \mathrm{ml}$, and $\mathbf{d} 6.25 \mu \mathrm{g} / \mathrm{ml}$. As a virus control, three wells of non-treated CHIKV-infected cells, (e), were used. As vehicle control, three wells of non-infected Vero cells, (f), were monitored

such as sarcoma, lung cancer and ovarian cancer. But it can become toxic at certain concentrations for different cells. Therefore, we used cisplatin as a control with known cytotoxicity. Our cytotoxicity evaluation of cisplatin through the RTCA method showed the efficacy and sensitivity of RTCA in detecting cytotoxic effects in a real-time monitoring frame and a well-defined dose-dependent manner.

In this study, we observed different times of onset of CPE for both RTCA and MTS assay as a conventional end-point assay. The time point for onset of CPE for antiviral assay evaluated by RTCA was at approximately
$14 \mathrm{~h}$ earlier compared to the MTS. The curve generated by the RTCA software showed a decline at $34 \mathrm{~h}$ postinfection, while for the MTS assay, at least $48 \mathrm{~h}$ passed before significant changes could be identified through the absorbance reading. The $\mathrm{IC}_{50}$ of the conventional assay exhibited vast differences between both days of treatment compared to the $\mathrm{IC}_{50}$ computed by RTCA, which showed a consistent and precise result through real-time monitoring. The graph from the MTS assay did not show resilient significant changes in ribavirin treatment at 48 and $72 \mathrm{~h}$. However, we observed a dosedependent manner curve in RTCA analysis after ribavirin

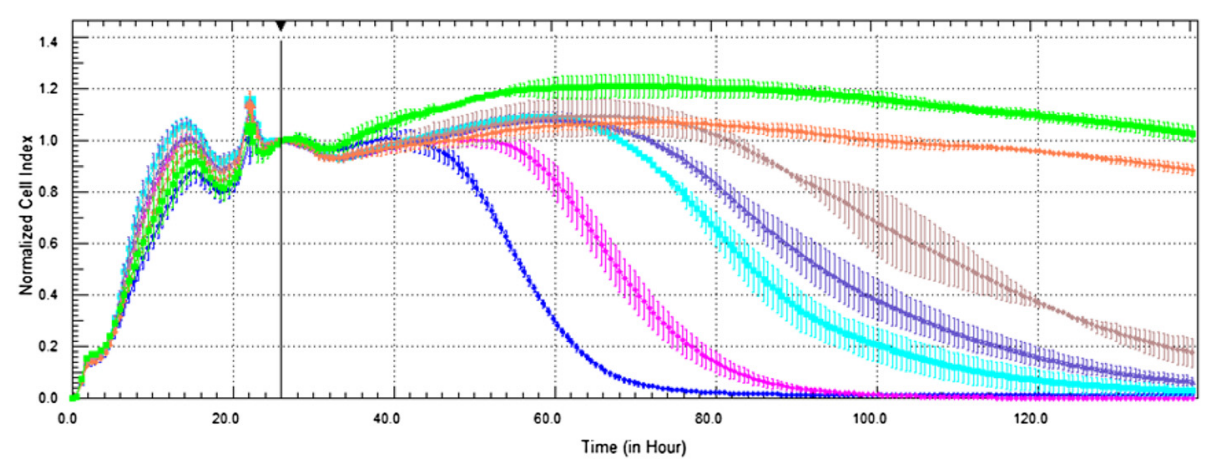

Fig. 7 The Viral Titration of Vero Cell Infected with CHIKV Evaluated by RTCA. Measuring cell impedance every 2 minutes by RTCA monitored the viral dose-dependency effect of various dilutions of CHIKV inoculum on the proliferation, spreading and adhesion of cells. The black vertical line indicates the normalisation of the $\mathrm{Cl}$ time point at $26 \mathrm{~h}$ subsequent to CHIKV infection of the Vero cell line. Coloured curves represent the Vero cells infected with different concentrations of CHIKV. Blue line: $10^{-1} \mathrm{CHIKV}$; Pink line: $10^{-2} \mathrm{CHIKV}$; Turquoise line: $10^{-3} \mathrm{CHIKV}$; Purple line: $10^{-4}$ CHIKV; Grey line: $10^{-5} \mathrm{CHIKV}$ and Orange line: $10^{-6} \mathrm{CHIKV}$; Green line: negative control (without CHIKV infection). Each data point signifies the average \pm standard deviation and was analysed in triplicate 
treatment for CHIKV-infected Vero cells, as the CI value started to decrease at approximately $34 \mathrm{~h}$ post infection and treatment. This finding indicated that RTCA technology was capable of detecting real-time changes in quantification of virus-induced $\mathrm{CPE}$ and the behaviour of the cellular mechanism when exposed to a drug or compound, which cannot be observed through the conventional methods.

Cell quality control and stability are major concerns due to the amplified dependence on cells in drug discovery $[20,21]$. In traditional methods, phenotypic analysis and viability are examined by microscopy and dye staining techniques, which, in addition to being timeconsuming, are mainly carried out at a single time point. Kirstein et al. [20] have shown similar proliferation kinetic profiles for various cell types, which explains a quantitative account of their cellular behaviour. In comparison to conventional cell-based assays, RTCA is a practical method whereby all the information regarding cell activities throughout the incubation period is automatically recorded and monitoring is continuous.

As a diagnostic tool, this information can be effectively used for cellular quality control, which could be measured based on the RTCA technology. To encourage more investigators to use RTCA in primary toxicity screening, emphasising the close correlation between cellular impedance measurements with numerous compounds is considered to be vital. However, the limited usage of RTCA assay, which works best with adhered cells and comes at a great expense in comparison with traditional facilities, is a restricting factor for RTCA.

\section{Conclusion}

In conclusion, regardless of restrictions, RTCA technology seems to be a prevailing and trustworthy tool in research innovation due to the realistic throughput, the opportunity to carry out quality control and technical optimisation, and the likelihood of analysing real-time cell reactions to antiviral agents for the development of pharmaceutical products in the early stages [22]. This system can produce predictive facts at the hit-to-lead phase and as a result, diminish the destruction rate due to the safety and efficacy associated with substantial savings for the advanced stages of antiviral drug development [23]. In addition, unlike the conventional end-point assays, RTCA provides time-based biological information at the interface between cells and toxicants.

\footnotetext{
Abbreviations

RTCA: Real-time cell analyser; CHIKV: Chikungunya virus; CPE: Cytopathic effects; DMSO: Dimethyl sulfoxide; Cl: Cell Index; MNTD: Maximum non-toxic dose; $\mathrm{TCID}_{50}$ : Tissue culture infectious dose; $\mathrm{IC}_{50}$ : Inhibitory concentration; $\mathrm{CC}_{50}$ : Cytotoxicity concentration..
}

\section{Competing interests}

The authors have declared that no competing interests exist.

\section{Authors' contributions}

KZ designed the study. SMM and MHS carried out the experiments. KZ, SAB, SMM and MHS have done the data analysis. SMM drafted the manuscript and MHS, KZ and SAB edited the manuscript. All authors read and approved the final manuscript.

\section{Acknowledgment}

The authors would like to thank the Ministry of Higher Education (MOHE), Malaysia, for awarding the High Impact Research (HIR) MOHE Grant (E000013-20001). We would also like to thank the University of Malaya for the UMRG fund (RG356-15AFR), flagship grant (FL001-13HTM) and postgraduate (PPP) fund (PG037-2013B), which covered the expenses of this study.

Received: 12 August 2015 Accepted: 20 September 2015

Published online: 09 November 2015

\section{References}

1. Rizzo F, Cerutti F, Ballardini M, Mosca A, Vitale N, Radaelli MC, et al. Molecular characterization of flaviviruses from field-collected mosquitoes in northwestern Italy, 2011-2012. Parasit Vectors. 2014;7:1-11.

2. Tchankouo-Nguetcheu S, Bourguet E, Lenormand P, Rousselle J-C, Namane A, Choumet $V$. Infection by chikungunya virus modulates the expression of several proteins in Aedesaegypti salivary glands. Parasit Vectors. 2012;5:1-11.

3. Ross RW. The new ala epidemics III: the virus isolation, pathogenic properties and relationship to the epidemics. J Hyg. 1956;54:177-91.

4. Coffey LL, Failloux AB, Weaver SC. Chikungunya virus-vector interactions. Viruses. 2014;6:4628-63.

5. Lundstrom K. Alphavirus-Based Vaccines. Viruses. 2014;6:2392-415.

6. Alvarez M, Rodriguez-Roche R, Bernado L, Morier L, Guzman MG. Improved dengue virus plaque formation on BHK21 and LLCMK 2 cells: evaluation of some factors. Dengue Bull. 2005;29:49-57.

7. Wang P, Henning SM, Heber D. Limitations of MTT and MTS-Based assays for measurement of antiproliferative activity of green tea polyphenols. PLoS ONE. 2010; 5(4): doi:10.1371/journal.pone.0010202

8. Slanina H, König A, Claus H, Frosch A, Schubert-Unkmeir A. Real-time impedance analysis of host cell response to meningococcal infection. J Microbiol Methods. 2011;84:101-8.

9. Leme DM, Grummt T, Heinze R, Sehr A, Skerswetat M, de Marchi MR, et al. Cytotoxicity of water-soluble fraction from biodiesel and its diesel blends to human cell lines. Ecotoxicol Environ Saf. 2011;74:2148-55.

10. Keogh R. New technology for investigating trophoblast function. Placenta. 2010;31:347-50.

11. Abassi YA, Xi B, Zhang W, Ye P, Kirstein SL, Gaylord MR, et al. Kinetic cell-based morphological screening: Prediction of mechanism of compound action and off-target effects. Chem Biol. 2009;16:712-23.

12. Solly K, Wang X, Xu X, Strulovici B, Zheng W. Application of real-time cell electronic sensing (RT-CES) technology to cell-based assays. Assay Drug Dev Technol. 2004;2:363-72.

13. Ravichandran R, Maniam M. Ribavirin theraphy for Chikungunya arthritis. J Infect Dev Ctries. 2008:2:140-2.

14. Briolant S, Garin D, Scaramozzino N, Jouan A, Crance JM. In vitro inhibition of Chikungunya and Semliki Forest virus replication by antiviral compound: synergistic effect of interferon-alpha and ribavirin combination. Antiviral Res. 2004;61:111-7.

15. Sam IC, Chan YF, Chan SY, Loong SK, Chin HK, Hooi PS, et al. Chikungunya virus of Asian and Central/East African genotypes in Malaysia. J Clin Virol. 2009;46:180-3.

16. Reed LJ, Muench HA. Simple method of estimating fifty per cent end points. Am J Hyg. 1938;27:493-7.

17. Kho D, Macdonald C, Johnson R, Unsworth CP, O'Caroll SJ, du Mez E, et al. Application of XCELLigence RTCA biosensor technology for revealing the profile and window of drug responsiveness in real time. Biosensors. 2015;5:199-222.

18. AbuBakar S, Shu MH, Johari J, Wong PF. Senescence affects endothelial cells susceptibility to dengue virus infection. Int J Med Sci. 2014;11:538-44.

19. Hug TS. Biophysical methods for monitoring cell-substrate interactions in drug discovery. Assay Drug Dev Technol. 2003;1:479-88.

20. Kirstein SL, Atienza JM, Xi B, Zhu J, Yu N, Wang X, et al. Live cell quality control and utility of real-time cell electronic sensing for assay development. Assay Drug Dev Technol. 2006;4:545-53. 
21. Stacey G. Validation of cell culture media components. Hum Fertil. 2004;7:113-8.

22. Atienzar FA, Tilmant K, Helga H, Toussaint GG, Speeckaert S, Hanon E, et al. The use of real-time cell analyzer technology in drug discovery: Defining optimal cell culture conditions and assay reproducibility with different adherent cellular models. J Biomol Screen. 2011;16:575-85.

23. Kola I. The state of innovation in drug development. Clin Pharmacol Ther. 2008;83:227-30.

Submit your next manuscript to BioMed Central and take full advantage of:

- Convenient online submission

- Thorough peer review

- No space constraints or color figure charges

- Immediate publication on acceptance

- Inclusion in PubMed, CAS, Scopus and Google Scholar

- Research which is freely available for redistribution 